\title{
Presynaptic Effects of NMDA in Cerebellar Purkinje Cells and Interneurons
}

\author{
M. Glitsch and A. Marty \\ Arbeitsgruppe Zelluläre Neurobiologie, Max-Planck-Institut für biophysikalische Chemie, 37077, Göttingen, Germany
}

NMDA receptors (NMDARs) are generally believed to mediate exclusively postsynaptic effects at brain synapses. Here we searched for presynaptic effects of NMDA at inhibitory synapses in rat cerebellar slices. In Purkinje cells, application of NMDA enhanced the frequency of miniature IPSCs (mIPSCs) but not that of miniature EPSCs (mEPSCs). This increase in frequency was dependent on the external $\mathrm{Mg}^{2+}$ concentration. In basket and stellate cells, NMDA induced an even larger mIPSC frequency increase than in Purkinje cells, whereas mEPSCs were again not affected. Moreover, NMDA induced an inward current in both types of interneuron, which translated into a small depolarization ( $10 \mathrm{mV}$ for $30 \mu \mathrm{M}$ NMDA) under current-clamp conditions. In paired recordings of connected basket cell-Purkinje cell synapses, depolarizations of 10-30 $\mathrm{mV}$ applied to the basket cell soma enhanced the frequency of

Postsynaptic NMDA receptors (NMDARs) play a fundamental role in synaptic transmission in the brain, where they mediate an almost ubiquitous component of excitatory synaptic currents (Collingridge et al., 1988; Hestrin et al., 1990) and where they participate in diverse processes such as neuronal plasticity (Collingridge and Singer, 1990) and neurotoxicity (Meldrum and Garthwaite, 1990). By contrast, presynaptic actions of NMDARs are far less well documented.

Several recent reports provide immunohistochemical evidence for NMDARs on presynaptic terminals (e.g., in the visual cortex: Aoki et al., 1994; DeBiasi et al., 1996; in the spinal cord: Liu et al., 1994; in the cerebellum: Petralia et al., 1994; in the amygdala: Farb et al., 1995). This raises the intriguing possibility that, in addition to its well characterized postsynaptic actions, NMDARs might also regulate neurotransmitter release. Indeed there is evidence that NMDAR activation can increase the release of noradrenaline (Pittaluga et al., 1990; Wang et al., 1992) and of dopamine (Krebs et al., 1991; Wang, 1991) in synaptosomes. At neuromuscular synapses from Xenopus in culture, glutamate, kainate, or NMDA has been shown to enhance transmitter release by activation of axonal receptors. This effect was resistant to addition of tetrodotoxin (TTX; Fu et al., 1995). In the spinal cord of the lamprey, inward currents reflecting the activation of both AMPA-selective receptors and of NMDARs were obtained in

\footnotetext{
Received March 19, 1998; revised Oct. 5, 1998; accepted Oct. 19, 1998.

We thank C. Pouzat and P. Vincent for providing analysis software, and A. Fleig, A. B. Parekh, and I. Llano for comments on this manuscript.

Correspondence should be addressed to Dr. A. Marty, Arbeitsgruppe Zelluläre Neurobiologie, Max-Planck-Institut für biophysikalische Chemie, Göttingen, Germany.

Dr. Glitsch's present address: University Laboratory of Physiology, Parks Road, Oxford OX1 3PT, UK.

Copyright (C) 1999 Society for Neuroscience $\quad 0270-6474 / 99 / 190511-09 \$ 05.00 / 0$
}

postsynaptic mIPSCs, suggesting that somatic depolarization was partially transmitted to the terminals in the presence of tetrodotoxin. However, this effect was small and unlikely to account fully for the effects of NMDA on mIPSCs. Consistent with a small number of dendritic NMDARs, evoked EPSCs in interneurons had a remarkably small NMDA component. Evoked IPSCs at interneuron-interneuron synapses were inhibited by NMDA, and the rate of failures was increased, indicating again a presynaptic site of action. We conclude that activation of NMDARs in interneurons exerts complex presynaptic effects, and that the corresponding receptors are most likely located in the axonal domain of the cell.

Key words: cerebellum; GABA; NMDA; presynaptic receptors; axon; stellate cell; basket cell

axonal recordings; these currents may correspond to the activation of receptors of axo-axonal synapses (Cochilla and Alford, 1997). In mammalian brain slices, there have been a few reports of presynaptic effects of ionotropic glutamate receptor agonists on synaptic currents (for review, see McGehee and Role, 1996; see further references in Discussion). In the entorhinal cortex, application of the selective NMDAR antagonist D-APV leads to a decrease in the frequency of miniature EPSCs (mEPSCs) (Berretta and Jones, 1996), indicating a facilitatory presynaptic role for NMDARs. Despite these scattered reports, however, the physiological significance of presynaptic NMDARs has remained largely unexplored.

In Purkinje cells of rat cerebellar slices, bath application of NMDA lead to an increase in the frequency of spontaneous inhibitory synaptic currents (Farrant and Cull-Candy, 1991; Llano et al., 1991). However, just how NMDA accomplished this was not investigated. If, as commonly assumed, such effects were caused by the increase in the firing of presynaptic neurons after activation of "postsynaptic" (somatodendritic) receptors, then they should be abolished by application of TTX. In a recent study of presynaptic metabotropic glutamate receptors at inhibitory synapses onto Purkinje cells, we noticed that the unspecific glutamatergic agonist L-AP3 increased the frequency of spontaneous IPSCs, that this effect was blocked by the specific NMDAR antagonist APV, and that it was resistant to the application of TTX (Glitsch et al., 1996). These results implied that NMDA could exert a presynaptic action at this synapse. Here we investigate this possibility further.

\section{MATERIALS AND METHODS}

Tissue preparation. Sagittal cerebellar slices were prepared from rats aged 12-14 d, after the procedure described by Llano et al. (1991). Briefly, rats were decapitated after cervical dislocation, and the cerebellar vermis was 
dissected out and glued to the stage of a vibroslicer after a cooling period of 2-4 min in ice-cold bicarbonate-buffered saline (BBS; see composition below). Slices of 180-200 $\mu \mathrm{m}$ thickness were consequently cut and incubated in oxygenated BBS at $31-33^{\circ} \mathrm{C}$ for at least $45 \mathrm{~min}$ before their use in electrophysiological recordings.

Electrophysiological recordings. Tight-seal whole-cell recordings were obtained from Purkinje cells and interneurons as explained in Llano et al. (1991) and Llano and Gerschenfeld (1993). During experiments, slices were visualized through a $63 \times$ water immersion objective. Basket and stellate cells were differentiated on the basis of their position within the molecular layer: interneurons in the lower third were considered basket cells, and those in the upper two thirds were considered stellate cells (Palay and Chan-Palay, 1974).

The cell surface was not cleaned before recording. Experiments were performed with an EPC-9 patch-clamp amplifier (Heka Electronics, Lambrecht, Germany) and an additional EPC-7 patch-clamp amplifier (List Medical, Darmstadt, Germany) in the case of paired recordings. Patch-clamp pipettes had resistances of 2-2.5 $\mathrm{M} \Omega\left(\mathrm{Cs}^{+}\right.$-containing internal solution for recordings from Purkinje cells; see composition below) or of 4-5 $\mathrm{M} \Omega\left(\mathrm{K}^{+}\right.$-containing internal solution for recordings from interneurons; see composition below). Pipettes were coated with dental wax to reduce the input capacitance during recording. Cancellation of capacitive current and series resistance compensation $(\sim 70 \%)$ were performed for Purkinje cell recordings as described in Llano et al. (1991). Experiments were abandoned when series resistance increased $>12$ (Purkinje cells) or $20 \mathrm{M} \Omega$ (interneurons) or when the holding current exceeded -500 (Purkinje cells) or $-70 \mathrm{pA}$ (interneurons), measured at a holding potential of $-60 \mathrm{mV}$. For current-clamp experiments, a holding current was applied such that the resting potential was $-60 \mathrm{mV}$.

Paired recordings. For paired recordings, a whole-cell recording was first established on a Purkinje cell. Cell-attached recordings were then obtained for one or several basket cells located within $50 \mu \mathrm{m}$ (distance measured between somata centers) of the Purkinje cell. Spontaneous action potentials (Llano and Gerschenfeld, 1993) were monitored from the basket cell, and if a functional connection was observed, presynaptic and postsynaptic signals were recorded for 1-2 min. The experiment proceeded by addition of TTX to the bath, which resulted in a loss of presynaptic action potentials. In TTX-containing BBS, the whole-cell configuration was also established in the basket cell. From a holding potential of $-60 \mathrm{mV}$, repetitive cycles of 1-sec-long depolarizing steps were applied to the basket cell immediately afterward, and the corresponding miniature IPSCs (mIPSCs) were registered in the Purkinje cell. After breaking into the basket cell, recordings never exceeded 10 min. This procedure allowed to minimize the rundown of the synaptic connection that occurs at this synapse after the onset of presynaptic whole-cell recording (Vincent and Marty, 1996).

Evoked IPSCs and EPSCs. Evoked IPSCs and EPSCs were obtained in interneurones using a saline-filled pipette as stimulation electrode. Voltage pulses $(20-90 \mathrm{~V}$; duration, $0.4 \mathrm{msec}$; rate, $0.33-0.5 \mathrm{~Hz}$ ) were applied between the pipette interior and a platinum electrode coiled around the pipette. To obtain evoked IPSCs, the stimulation pipette was positioned in the molecular layer, $\sim 100 \mu \mathrm{m}$ away from the recorded cell, and the bath was perfused with NBQX. To obtain evoked EPSCs, the stimulation pipette was positioned in the granule cell layer, $\sim 50 \mu \mathrm{m}$ away from the Purkinje cell layer, and the bath was perfused with bicuculline.

In the analysis of evoked IPSCs (see Fig. 8), failure rates were determined by counting events with an onset occurring during a time window that was determined empirically from the control data (typically, 1-4 msec after each stimulation artifact).

Analysis. Miniature synaptic currents were analyzed off-line using an event-detection routine. Detection thresholds were adjusted between 8 and $15 \mathrm{pA}$ for both Purkinje cells and interneurons, depending on the noise of the recording. In experiments performed on Purkinje cells, the ionotropic glutamate antagonist NBQX (see below) was added to the saline to block mEPSCs. NBQX was not included in miniature current recordings on interneurons, so that in these experiments $\mathrm{mEPSCs}$ were recorded together with $\mathrm{mIPSCs}$. However, the decay kinetics of mEPSCs are much faster than that of mIPSCs (Llano and Gerschenfeld, 1993), allowing unambiguous distinction of the two classes of events during analysis.

Paired recording experiments started with an initial period during which the presynaptic interneuron was recorded with the cell-attached configuration. To analyze the results of this first part, presynaptic action currents were identified using a spike detector. Postsynaptic traces were aligned with respect to the spikes and were averaged to calculate the mean amplitude of evoked IPSCs.

Statistical deviations from mean values given in the text, and error bars in figures, indicate \pm SEM across experiments, $n$ being the number of experiments.

Bath perfusion. The recording chamber was perfused at a rate of 1-1.5 $\mathrm{ml} / \mathrm{min}$ with BBS. Experiments were performed at room temperature $\left(22-25^{\circ} \mathrm{C}\right)$

To examine the effect of a drug or a modified external solution on miniature synaptic currents, membrane currents were recorded over a control period of $3 \mathrm{~min}$ in BBS, then the bath was exchanged to the test solution. After a period of 3-4 min to allow complete bath exchange, data acquisition was resumed. Recordings were typically of 3 min duration under each experimental condition. Only one cell per slice was used to circumvent possible long-term effects of the drugs used.

Solutions and drugs. The standard external solution (BBS) contained (in mM): $125 \mathrm{NaCl}, 2.5 \mathrm{KCl}, 2 \mathrm{CaCl}_{2}, 1 \mathrm{MgCl}_{2}, 1.25 \mathrm{NaH}_{2} \mathrm{PO}_{4}, 26$ $\mathrm{NaHCO}_{3}$, and 10 glucose, $\mathrm{pH} 7.4$ when equilibrated with a mixture of $95 \% \mathrm{O}_{2}$ and $5 \% \mathrm{CO}_{2}$. In experiments in which the effect of extracellular $\mathrm{Mg}^{2+}$ on NMDA-induced synaptic currents was investigated, either the external solution contained no $\mathrm{MgCl}_{2}$ or the concentration was raised to $8 \mathrm{mM} \mathrm{MgCl}_{2}$ without changing any other component.

The intracellular solution for Purkinje cells consisted of (in mM): 150 CsCl, 10 HEPES, 1 EGTA 0.1 $\mathrm{CaCl}_{2}$, 4.6 Na-ATP, 0.4 Na-GTP, and 4.6 $\mathrm{MgCl}_{2}$. The internal solution for interneurons was the same, except that $150 \mathrm{~mm} \mathrm{CsCl}$ was substituted by $150 \mathrm{~mm} \mathrm{KCl}$. The $\mathrm{pH}$ was set to 7.3 with $\mathrm{CsOH}$ or $\mathrm{KOH}$, respectively.

NMDA, (-)-bicuculline methochloride (bicuculline), 6-nitro-7sulfamoylbenzo[f]quinoxaline-2,3-dione (NBQX), and D(-)-2-amino-5phosphonopentanoic acid (D-APV) were obtained from Tocris Cookson (Bristol, UK). CGP 62349 was kindly provided by Ciba Geigy. All other drugs and chemicals were purchased from Sigma (St. Louis, MO). Drug stocks were prepared as follows: $100 \mathrm{mM}$ NMDA, $10 \mathrm{mM}$ D-APV, and 1 mM NBQX in equimolar NaOH; 10 mm CGP 62349 in DMSO; and $1 \mathrm{~mm}$ bicuculline in $\mathrm{H}_{2} \mathrm{O}$. TTX was purchased as $1 \mathrm{mg}$ aliquots containing $5 \mathrm{mg}$ citrate buffer; $0.2 \mathrm{~mm}$ stocks were prepared in $\mathrm{H}_{2} \mathrm{O}$. Stocks were aliquoted, frozen, and dissolved daily in BBS to reach the desired concentration.

\section{RESULTS}

\section{NMDAR activation leads to an increase in the frequency of mIPSCs in Purkinje cells}

mIPSCs were recorded in Purkinje cells dialyzed with a high intracellular $\mathrm{Cl}^{-}$concentration solution at a holding potential of $-60 \mathrm{mV}$. Amplitudes ranged from $\sim 10 \mathrm{pA}$ to several hundreds of pA (Fig. $1 A$, top left panel). In these experiments, $\mathrm{Na}^{+}$dependent action potentials and glutamatergic synaptic currents were blocked, respectively, with $0.2 \mu \mathrm{M}$ TTX and $10 \mu \mathrm{M}$ NBQX. Under these conditions, bath-application of $15 \mu \mathrm{M}$ NMDA led to a massive increase in the frequency of mIPSCs (top right panel). In agreement with previous work (Llano et al., 1991), there was no effect of NMDA on the holding current of the Purkinje cell.

The specific NMDAR antagonist D-APV blocked the NMDAinduced frequency increase (Fig. $1 \mathrm{~A}$, bottom panel). Figure $1 B$ shows pooled data from seven NMDA-treated Purkinje cells in the absence and presence of D-APV. NMDA induced a large and consistent frequency increase, and this effect was reduced almost 10 -fold in the presence of $50 \mu \mathrm{M}$ D-APV. These results indicate that activation of NMDARs results in an increase in the frequency of mIPSCs in Purkinje cells.

Application of D-APV slightly decreased the frequency of mIPSCs (to $82 \pm 5 \%$ of the control, $n=9$; Fig. 2). In six of nine cells, this decrease was statistically significant (Kolmogorov-Smirnov test; $p<0.05)$, whereas there was no significant change in the remaining three cells. The mean amplitude of mIPSCs was not modified by D-APV (mean ratio to the control, $95 \pm 6 \% ; n=9$ ). These results indicate that a tonic activation of NMDARs, caused by background glutamate, may permanently enhance the rate of miniatures. 
A
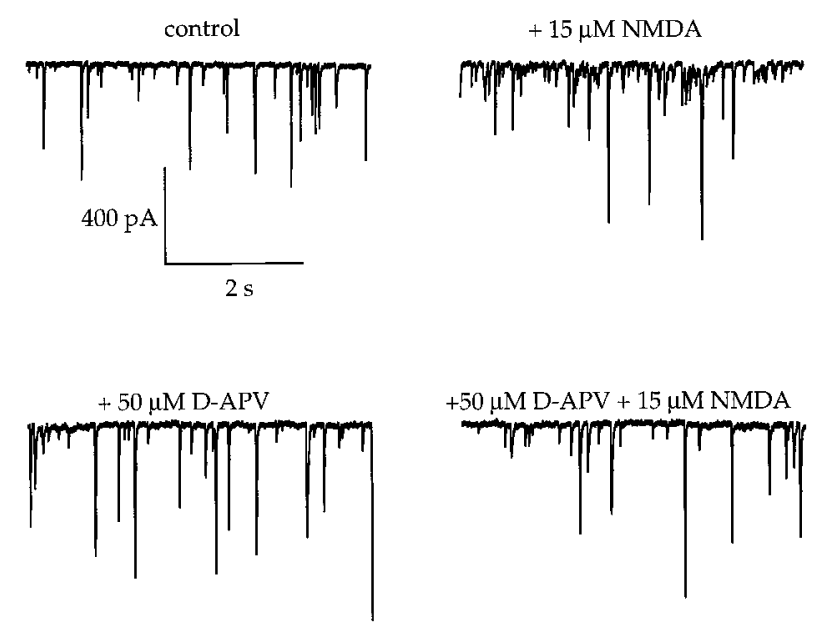

B

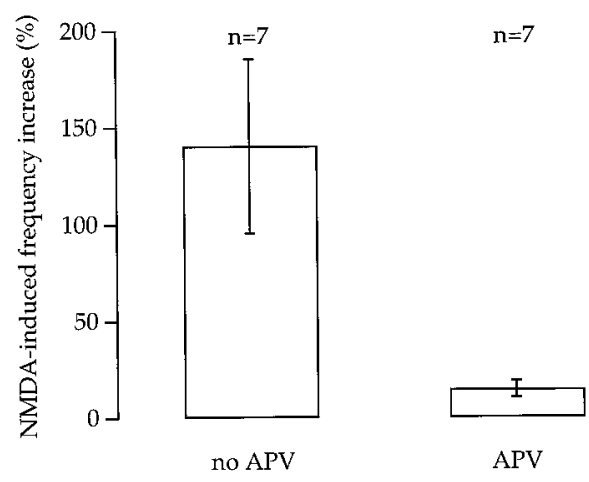

Figure 1. NMDAR activation increases the mIPSC frequency in Purkinje cells. A, Top two traces show mIPSCs recorded from a representative Purkinje cell under control conditions $(l e f t)$ and in the presence of 15 $\mu \mathrm{M}$ NMDA (right). Bottom traces, After washing NMDA, the bath was perfused with a solution containing $50 \mu \mathrm{M}$ D-APV. Further addition of 15 $\mu \mathrm{M}$ NMDA did not alter the pattern of mIPSCs. $B$, Pooled results from seven experiments. In the absence of $50 \mu \mathrm{M}$ D-APV, $15 \mu \mathrm{M}$ NMDA leads to a $141 \pm 45 \%$ increase in the frequency of mIPSCs. In the presence of $50 \mu \mathrm{M} \mathrm{D}-\mathrm{APV}$, the increase in the frequency is almost completely blocked $(15 \pm 4 \%)$. All experiments were performed in the presence of $0.2 \mu \mathrm{M}$ TTX and $10 \mu \mathrm{M}$ NBQX.

\section{NMDA primarily enhances the frequency of small mIPSCs}

Close inspection of the traces in Figure $1 A$ and in similar experiments suggested that the NMDA-induced frequency increase concerned primarily small amplitude mIPSCs, whereas large amplitude mIPSCs were less affected. To quantify this effect, we compared the cumulated amplitude distributions of mIPSCs in control conditions (in the presence of TTX and NBQX) and after addition of NMDA. Figure 3 illustrates pooled amplitude histograms from all seven cells in control conditions (Fig. $3 A$ ), in NMDA (Fig. 3B), and for the difference events (NMDA-induced events; Fig. $3 C$ ). Clear differences can be seen in the corresponding cumulative histograms (Fig. 3D). In individual experiments, cumulative distributions of mIPSC amplitudes in the presence and absence of NMDA were statistically significant in six of seven
A
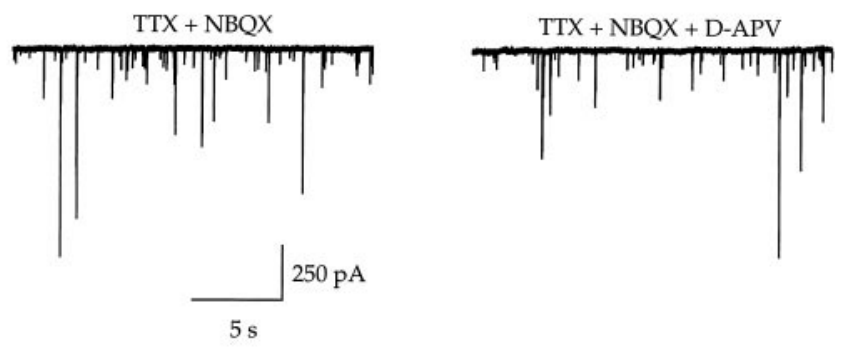

B
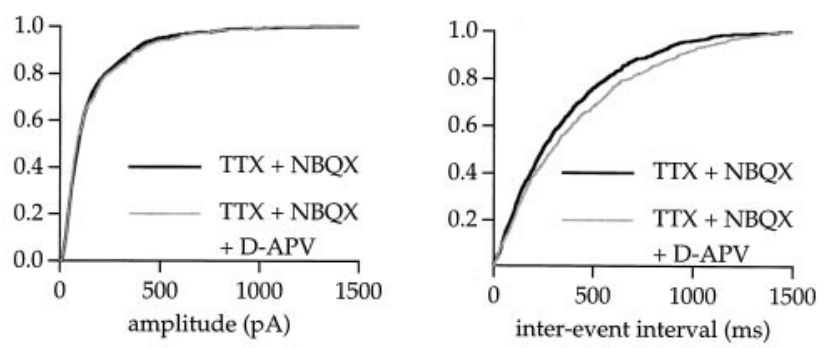

Figure 2. D-APV reduces the frequency of mIPSCs in Purkinje cells. $A$, Raw traces, showing mIPSCs under control conditions (left, $0.2 \mu \mathrm{M}$ TTX $+10 \mu \mathrm{M}$ NBQX) and after addition of $50 \mu \mathrm{M}$ D-APV (right). B, After addition of D-APV, the cumulated amplitude histogram is not modified (left), whereas the cumulated interval histograms indicate a change to a lower event frequency (right). Same cell as in $A$. Total number of events ( 5 min recording periods in each condition): 831 in control saline, and 615 in the presence of D-APV. Mean amplitudes: $166 \mathrm{pA}$ in control, and 170 pA in D-APV.

cells (Kolmogorov-Smirnov test; $p<0.01$ ). On average, NMDA decreased the mean current amplitude to $86 \pm 4 \%$ of control values $(n=7)$.

\section{NMDA selectively enhances GABA release}

The finding that NMDA selectively enhanced the frequency of small miniature synaptic currents was rather unexpected. In view of the recent demonstration of glycinergic currents in cerebellar Golgi cells (Dieudonné, 1995), the possibility was considered that NMDA was recruiting a previously unrecognized nonGABAergic, nonglutamatergic input to Purkinje cells. Therefore, the effects of NMDA were reinvestigated in the presence of bicuculline. To test simultaneously for possible effects of NMDA on mEPSCs, NBQX was omitted from these experiments. mEPSCs recorded in the presence of bicuculline had a mean amplitude of $29 \pm 3 \mathrm{pA}(n=7)$. Addition of NMDA under these conditions did not lead to any modification in mEPSC amplitude, nor to any increase in activity (control, $8 \pm 2 \mathrm{mEPSCs} / \mathrm{min}$; in NMDA, $6 \pm 3 \mathrm{mEPSCs} / \mathrm{min} ; n=7)$. After washing out bicuculline, NMDA evoked an increase in mIPSC frequency, confirming that NMDA was effective $(n=3)$. These results confirm that NMDA-induced events are GABAergic, and they show that the frequency increase is specific of inhibitory synapses.

\section{$\mathbf{M g}^{2+}$ dependence of NMDA effect}

It is well established that NMDA channels are blocked in a voltage-dependent manner by $\mathrm{Mg}^{2+}$ (Mayer et al., 1984; Nowak et al., 1984). All experiments described so far were performed in the presence of $1 \mathrm{~mm} \mathrm{Mg}{ }^{2+}$. To investigate the $\mathrm{Mg}^{2+}$ dependence of the NMDA effect, we established dose-response curves for 
A

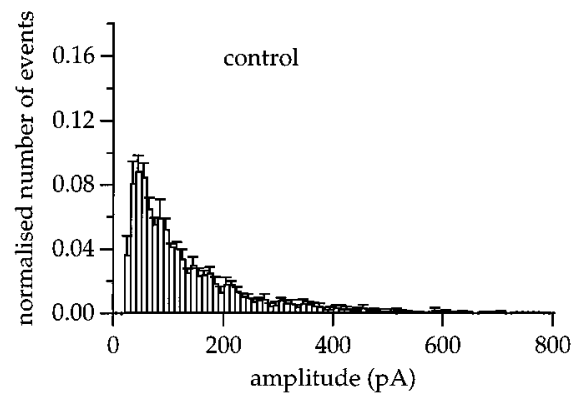

Figure 3. NMDAR activation preferentially increases the frequency of small events. $A$, Average amplitude distribution of mIPSCs of seven cells under control conditions $(0.2 \mu \mathrm{M}$ TTX and $10 \mu \mathrm{M}$ NBQX). Histograms were taken from 3-min-long recordings and were normalized to the total number of events. Bin width is $10 \mathrm{pA}$. $B$, Normalized average amplitude distribution of mIPSCs of the same cells in the presence of $15 \mu \mathrm{M}$ NMDA. $C$, Normalized average amplitude distribution of NMDA-induced events, obtained by subtracting the distributions in NMDA from the control ones. $D$, Comparison of integrals of the plots in $A-C$ (cumulative amplitude histograms). NMDA-induced events are on average smaller than control events.
C

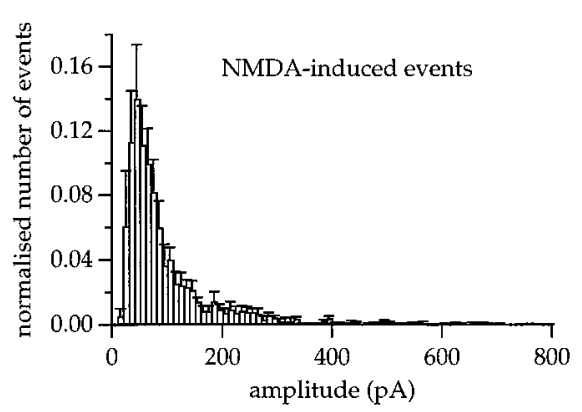

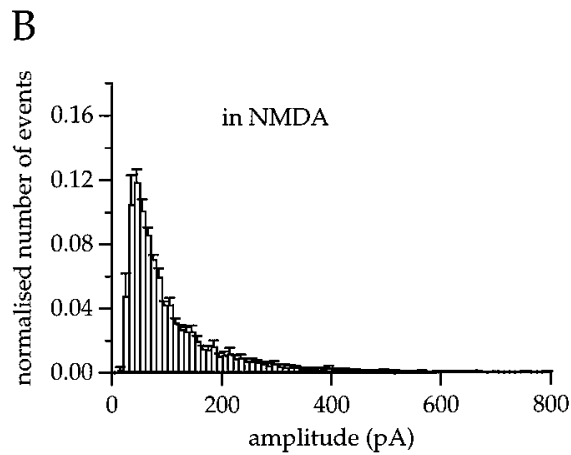

$\mathrm{D}$

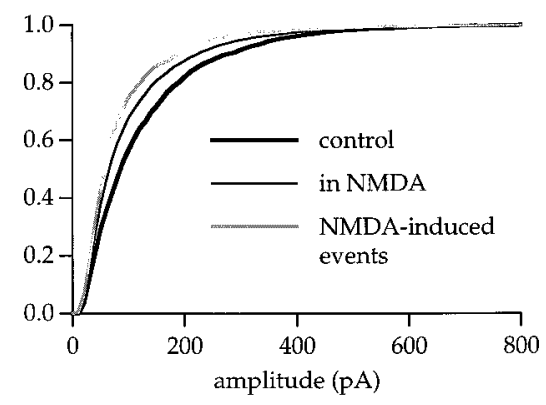

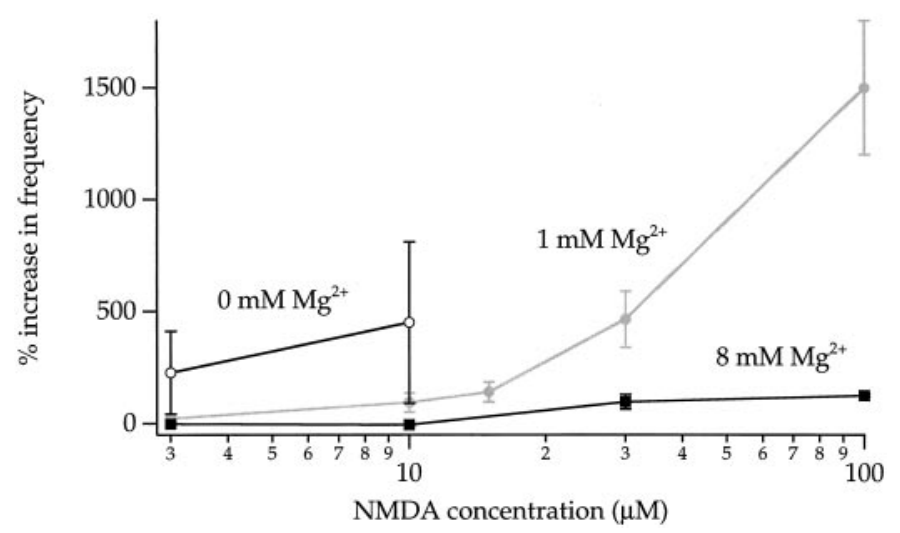

Figure 4. $\mathrm{Mg}^{2+}$ dependence of NMDA effect. Plot of NMDA-induced increase in mIPSC frequency in Purkinje cells in different external $\mathrm{Mg}^{2+}$ concentrations. Open circles, $0 \mathrm{mM} \mathrm{Mg}^{2+}$; gray circles, $1 \mathrm{mM} \mathrm{Mg}^{2+}$ (normal BBS); black squares, $8 \mathrm{~mm} \mathrm{Mg}^{2+}$. For $0 \mathrm{Mg}^{2+}$, only two NMDA concentrations were tested. Experiments were performed in the presence of $0.2-0.5 \mu \mathrm{M}$ TTX and $10 \mu \mathrm{M}$ NBQX $(n=3-7)$.

NMDA in external solutions containing different concentrations of $\mathrm{Mg}^{2+}$. As the extracellular $\mathrm{Mg}^{2+}$ concentration increased, the stimulatory effect of NMDA on synaptic activity was reduced (Fig. 4).

\section{NMDA enhances the mIPSC frequency in interneurons}

Purkinje cells receive inhibitory inputs from interneurons of the molecular layer, basket, and stellate cells (Llinas and Walton, 1990). It is therefore likely that the increase in mIPSCs observed in Purkinje cells was the result of NMDA acting on receptors located on these interneurons. Interneurons not only contact Purkinje cells but also make inhibitory contacts with each other (Palay and Chan-Palay, 1974). Because the effects of NMDA on Purkinje cell IPSCs were apparently presynaptic, it seemed plausible that interneuron-interneuron synaptic contacts would be influenced as well. NMDA $(30 \mu \mathrm{M})$ increased the frequency of
mIPSCs in both stellate and basket cells (Fig. $5 A, B$ ). The frequency ratio over control values was $24.1 \pm 10.6$ in basket cells $(n=6)$ and $21.7 \pm 3.4$ in stellate cells $(n=5)$ (pooled data, $23.0 \pm 5.8 ; n=11)$, and thus about fourfold bigger than in Purkinje cells $(5.6 \pm 1.3)$. This suggests that interneuron-interneuron synapses are more sensitive to NMDAR activation than Purkinje cell-interneuron synapses. Figure $5 C$ shows the amplitude distribution of mIPSCs for the same stellate cell as shown in $A$ under control conditions $(0.2 \mu \mathrm{M}$ TTX) and in the additional presence of $30 \mu \mathrm{M}$ NMDA. On average, both basket and stellate cells showed a slight, statistically insignificant mean amplitude increase in the presence of $30 \mu \mathrm{M}$ NMDA when compared with control (ratio of mean amplitude in $30 \mu \mathrm{M}$ NMDA and control, $1.15 \pm 0.24 ; n=11$; six basket cells and five stellate cells). Thus, the decrease in miniature size observed in Purkinje cells was not reproduced in interneurons.

To determine whether NMDA had a potentiating effect on mEPSCs in interneurons, we looked at the number of mEPSCs in $15 \mu \mathrm{M}$ bicuculline and compared it with the frequency of excitatory currents in $15 \mu \mathrm{M}$ bicuculline $+30 \mu \mathrm{M}$ NMDA. The control number of mEPSCs during a 3 min recording in bicuculline was $12 \pm 3$, and there was no difference to the number of mEPSCs recorded in the additional presence of NMDA $(13 \pm 2)$, suggesting that NMDA did not have any stimulatory effect on glutamate release ( $n=10$; six of which were stellate cells).

\section{NMDA induces inward current and somatic depolarization in interneurons}

In the above experiments examining the effects of NMDA on mIPSCs in interneurons, NMDA was found to reversibly induce an inward current (Fig. 5). To rule out the possibility that this current could be a consequence of an activation of $\mathrm{GABA}_{\mathrm{A}}$ receptors, because of the higher rate of mIPSCs in NMDA, we performed NMDA applications $(30 \mu \mathrm{M})$ in the presence of $15 \mu \mathrm{M}$ bicuculline. Under these conditions there was still a clear inward current response $(14 \pm 3 \mathrm{pA} ; n=10$ cells, six of which were 
A

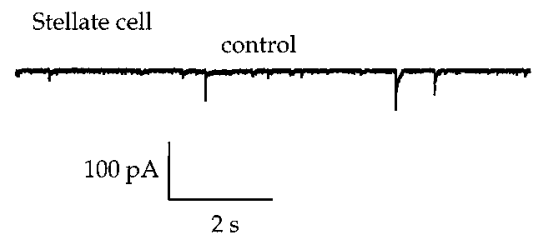

B

Basket cell

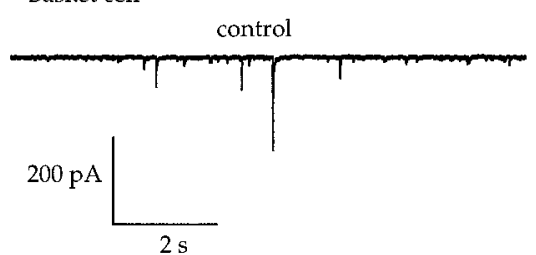

C

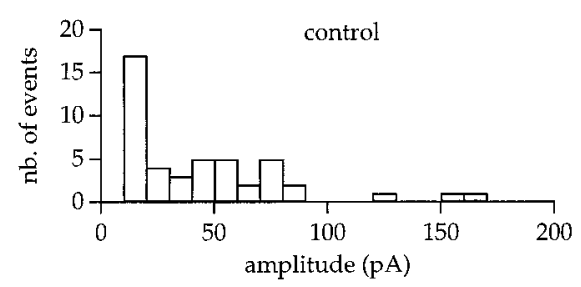

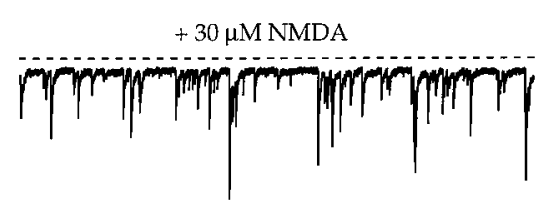
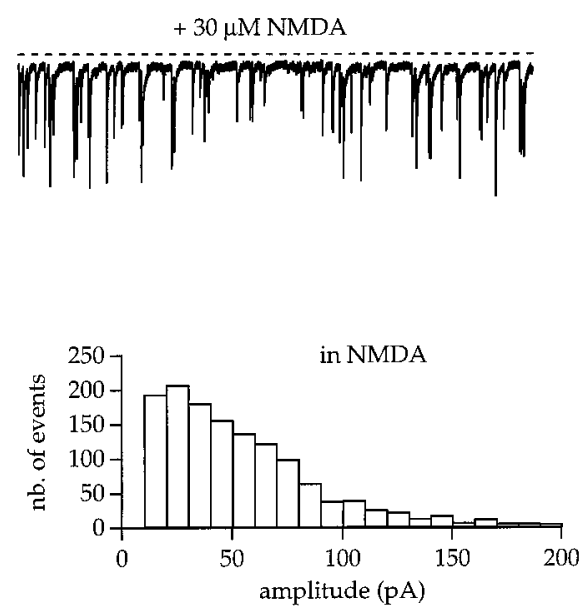

Figure 5. NMDA enhances synaptic activity in stellate and basket cells. $A$, Synaptic currents recorded from a representative stellate cell under control conditions $(0.2 \mu \mathrm{M}$ TTX, left trace $)$ and in additional presence of $30 \mu \mathrm{M}$ NMDA (right trace). $B$, Same as $A$, except that the recorded cell was a basket cell. Dotted lines in right traces in $A$ and $B$ indicate control holding current to show the NMDA-induced inward current in interneurons (26 and $24 \mathrm{pA}$, respectively). $C$, Amplitude distribution of mIPSCs of same stellate cell as in $A$ under control conditions $(0.2 \mu \mathrm{M}$ TTX, left $)$ and in additional presence of $30 \mu \mathrm{M}$ NMDA (right). Three minute recordings were used for each histogram. Ratio of mean amplitudes in NMDA-control, 1:3. stellate cells), suggesting that the inward current was directly due to activation of NMDARs in the recorded cells.

Membrane potential changes associated with the NMDAinduced current were measured under current clamp in the presence of $0.2 \mu \mathrm{M}$ TTX. Experiments were performed both in the presence and absence of bicuculline; no significant difference was found between the two conditions. Overall, application of $30 \mu \mathrm{M}$ NMDA induced a depolarization of $11 \pm 1 \mathrm{mV}(n=16$; pooled data of stellate and basket cells with or without bicuculline). There was no sign of regenerative voltage signals superimposed on these depolarizations.

\section{Can electrotonic spread of somatic depolarization account for the enhancement in MIPSC frequency by NMDA?}

The results obtained so far do not allow to specify whether the NMDARs responsible for the increase in the frequency of mIPSCs are located in the axon or in the somatodendritic compartment of the presynaptic interneurons. The fact that the frequency of mIPSCs was enhanced suggested at first sight an axonal location. However, we also considered the alternative hypothesis that the enhancement of mIPSC frequency would be secondary to activation of somatodendritic NMDARs in the presynaptic cells. Because the distance between soma and terminals is short in interneurons, this depolarization could be transmitted to the terminals despite the presence of TTX, as previously shown for $\mathrm{Cs}^{+}$-dialyzed cells (Vincent and Marty, 1996; Llano et al., 1997). Therefore, we next performed paired recordings between presynaptic basket cells and postsynaptic Purkinje cells to test if a somatic depolarization of the basket cell could lead to an increase in the mIPSC frequency in the Purkinje cell.

The experiments were performed on a series of seven connected basket cell-Purkinje cell pairs. In a first part of each experiment, the spontaneous firing of the presynaptic basket cell was monitored in the cell-attached configuration while the evoked IPSCs were registered with whole-cell recording (Fig. 6A1,A2).
The average evoked IPSC was $43 \mathrm{pA}$ in the example shown. This average value times the number of presynaptic action potentials was used to determine the "weight" of the connection (in this case, $2.4 \%$ ) by comparing it to the cumulative amplitude of all IPSCs recorded in the Purkinje cell over the same time period. Then TTX was added to the bath, leading to a loss of presynaptic action potentials. In TTX, a whole-cell recording was established in the basket cell, and 1 sec-long depolarizing steps were applied up to $-30 \mathrm{mV}$ to the presynaptic soma. Although no clear response could be distinguished in individual sweeps (Fig. 6B), on average the frequency of mIPSCs was correlated to the presynaptic steps (Fig. $6 C$; in the paired recording shown the frequency at $-30 \mathrm{mV}$ is 1.44 times higher than at $-60 \mathrm{mV}$, and this ratio is statistically different from 1 with $p<0.001$ ). The same trend, albeit weaker, was found in each of the other cases. Figure $6 D$ shows summary results for the seven experiments. At -30 $\mathrm{mV}$, the frequency ratio was on average $1.18 \pm 0.06(n=7 ; p<$ 0.05 ; test performed across experiments), but at $-50 \mathrm{mV}$ (roughly corresponding to the $11 \mathrm{mV}$ depolarization measured with $30 \mu \mathrm{M}$ NMDA), the ratio was only $1.08 \pm 0.05$. As will be further discussed below, such small changes are unlikely to underlie the effects of NMDA on mIPSCs.

\section{The NMDA component of evoked EPSCs in interneurons is small}

The amount of current elicited by bath applications of NMDA in interneurons seemed quite modest, as if few NMDARs resided on the dendritic tree. At all glutamatergic excitatory synapses investigated in the brain so far, with the only exception of parallel fiber EPSCs and climbing fiber EPSCs onto Purkinje cells, NMDA channels are responsible for a large part of the synaptic currents at positive potentials. The ratio of the peak current carried by NMDARs to that carried by AMPA receptors can be estimated by measuring at positive potentials the current during two time windows, one positioned 20-30 msec after the response onset, corresponding to the NMDA component, and the other a 


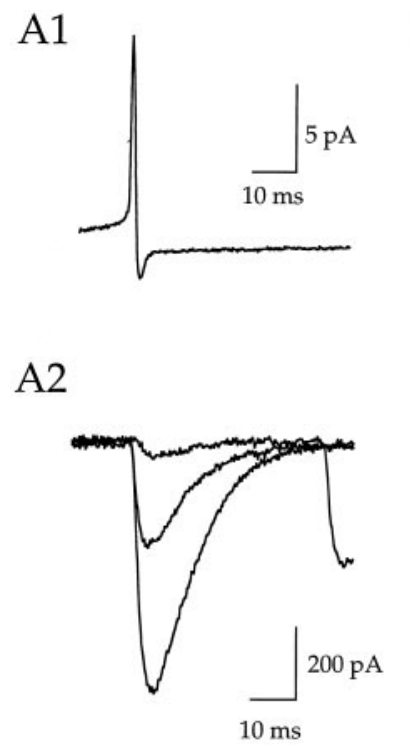

B

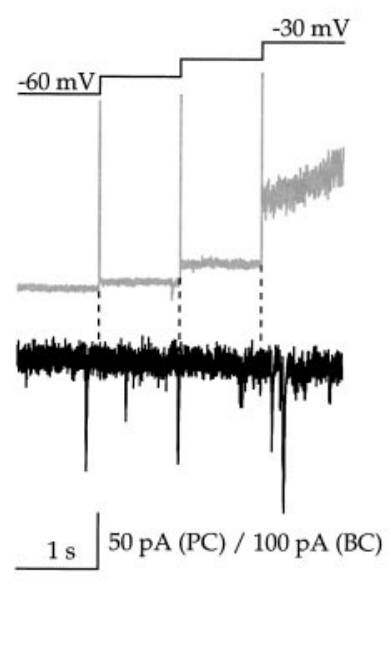

C

$\mathrm{D}$
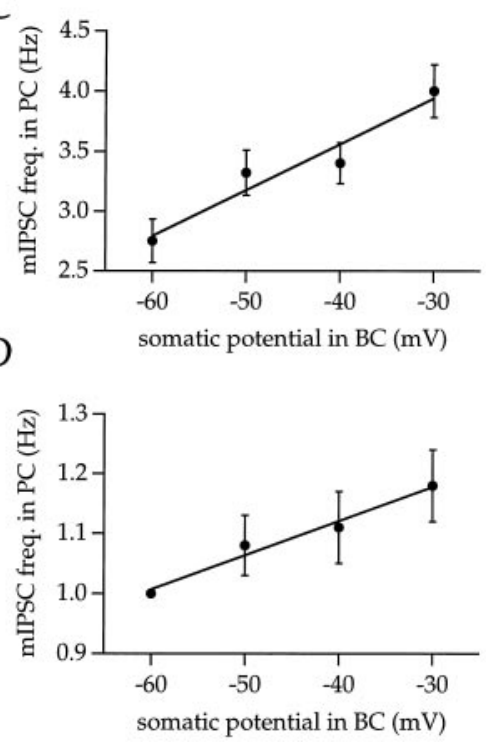

Figure 6. In TTX, somatic depolarization of an interneuron increases the mIPSC frequency in a postsynaptic Purkinje cell. All data obtained from paired recordings with presynaptic basket cells $(B C)$ and postsynaptic Purkinje cells $(P C) . A-C$ are from the same pair. $A 1$, Average of spikes recorded in the basket cell in cell-attached mode. $A 2$, Superimposed IPSCs recorded in the Purkinje cell. $B$, Results obtained after superfusion with $0.2 \mu \mathrm{M}$ TTX, shortly after breaking into the basket cell. Top trace shows the presynaptic depolarization protocol (repetitive cycles from -60 to $-30 \mathrm{mV}$ in $10 \mathrm{mV}$ steps, holding for $1 \mathrm{sec}$ at each potential). Gray and black traces show corresponding current trace recorded in the basket and Purkinje cell, respectively. $C$, Average mIPSC frequencies in the Purkinje cell ( $n=1001 \mathrm{sec}$ segments) for each $1 \mathrm{sec}$ segment, plotted against the somatic potential of the basket cell. $D$, Pooled data from seven pairs. Data in $D$ were normalized to the number of events at a presynaptic holding potential of $-60 \mathrm{mV}$.

Figure 7. The NMDA component of interneuron EPSCs is weak. EPSCs were evoked in an interneuron by extracellular stimulation in the granule cell layer. $A$, At $-60 \mathrm{mV}$, EPSCs had rapid decay kinetics, fluctuated markedly among trials, and displayed a fair amount of jitter in their onsets. At $+60 \mathrm{mV}$, only hints of a late component could be obtained in single traces. This component was insensitive to NBQX $(10 \mu \mathrm{M})$ but was blocked by further addition of D-APV $(20 \mu \mathrm{M})$. All solutions used contained $15 \mu \mathrm{M}$ bicuculline to block IPSCs. All four panels show five superimposed traces in each condition. $B$, Average traces at $-60 \mathrm{mV}$ in control conditions (bicuculline alone; thick black line), at $+60 \mathrm{mV}$ in control conditions (middle gray line), at $+60 \mathrm{mV}$ in the presence of NBQX (thin black line), and at

$+60 \mathrm{mV}$ after further addition of APV (light gray line). The inset shows the traces at $+60 \mathrm{mV}$ with enlarged vertical scale and slow time base. At +60 $\mathrm{mV}$, the peak currents of the AMPA and NMDA components are 59 and $2.4 \mathrm{pA}$, respectively, with a ratio of 25 -fold. Stimulation artifacts have been clipped off.

few msec after the response onset, corresponding to the AMPA component (Fig. 7). When applying this method to evoked EPSCs in interneurons, we found a mean ratio of the NMDA component to the AMPA component of $0.054 \pm 0.026(n=4)$. As shown in Figure 7, the identification of both components was confirmed by their respective sensitivity to D-APV and NBQX. These experiments show that, at excitatory synapses onto interneurons, the contribution of NMDA receptors to the total current is minimal. From a survey of similar results obtained on a number of mammalian brain synapses, it appears that the proportion of the NMDA component is markedly lower at interneurons than at any other preparation except for Purkinje cells. In the other synapses, the ratio of the NMDA component to the AMPA component ranged from $\sim 0.3$ (in medial septal neurons:
Schneggenburger et al., 1992) to $\sim 2.0$ (as for instance in stellate cells of the visual cortex: Stern et al., 1992). Thus, the strength of the NMDA contribution is 6-37 times lower at cerebellar interneuron synapses than in other synapses, and the number of NMDA receptors at somatodendritic postsynaptic sites appears indeed to be unusually low.

\section{NMDA inhibits evoked IPSCs in interneurons}

The finding of an enhanced rate of mIPSCs suggests that NMDA has a stimulatory action at interneuron synapses. However, past investigations have shown that evoked currents may be regulated differently from miniature currents (see Kondo and Marty, 1998, and further references within). The effects of NMDA were therefore investigated on evoked currents in interneuron-interneuron 

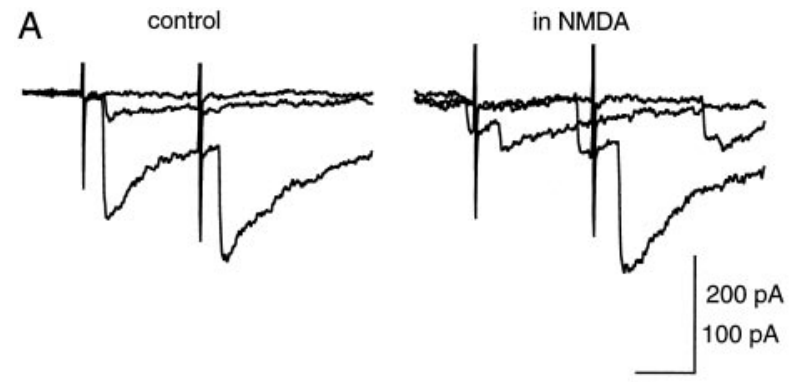

$10 \mathrm{~ms}$

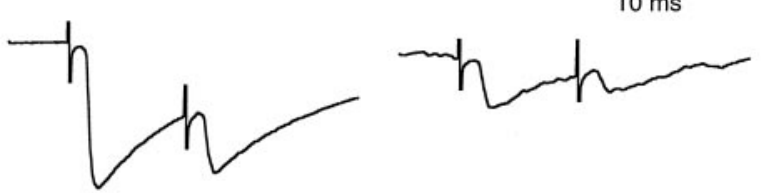

B

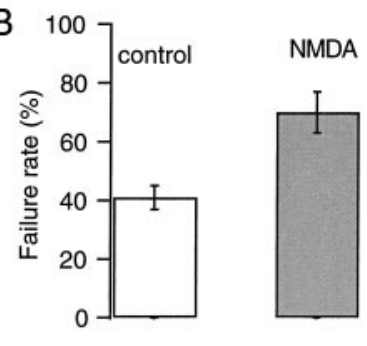

C

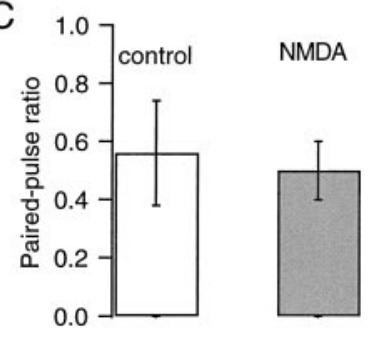

Figure 8. NMDA reduces evoked IPSCs in interneurons. $A$, Superimposed representative traces (three in each top panel) in control conditions (10 $\mu \mathrm{M} \mathrm{NBQX;} \mathrm{left),} \mathrm{and}$ after addition of $15 \mu \mathrm{M}$ NMDA (right). Each trace represents the response to a stimulation pair (interval, $20 \mathrm{msec}$; stimulation frequency, $0.33 \mathrm{~Hz}$ ). Note that addition of NMDA leads to an increase in the frequency of spontaneous IPSCs. Average responses in control conditions and in the presence of NMDA are shown in the bottom panels. Stimulation artifacts have been clipped off. $B$, Average failure rate results (responses to the first pulse of pairs) for seven experiments such as in $A$, including four cells in the presence of $0.5 \mu \mathrm{M}$ CGP 62349 and three cells without the blocker. $C$, Summary data for paired-pulse ratios in control conditions and in NMDA. synapses. Evoked IPSCs were obtained after extracellular stimulation within the molecular layer in the presence of NBQX. In all cases, NMDA application $(15 \mu \mathrm{M})$ resulted in a large increase in the rate of spontaneous IPSCs, from $3.1 \pm 1.6 \mathrm{~Hz}$ to $14.3 \pm 2.3$ $\mathrm{Hz}$, similar to that previously observed in Purkinje cells (Farrant and Cull-Candy, 1991; Llano et al., 1991). Frequency ratios ranged from 2 to 280 in individual experiments, with a geometric mean of 17. Because we were concerned that the increase in background activity may have led to the activation of $\mathrm{GABA}_{\mathrm{B}}$ receptors and, hence, to an inhibition of evoked IPSCs, the potent $\mathrm{GABA}_{\mathrm{B}}$ antagonist CGP $62349(0.5 \mu \mathrm{M}$; it was shown in separate experiments that this dose fully blocked inhibitory effects of baclofen on Purkinje cell IPSCs) was included in some experiments (four of seven). Results obtained with and without the antagonist were similar, and are pooled together hereafter. In all experiments, the mean amplitude of the evoked IPSC was reduced, with a mean ratio to the control of $0.29 \pm 0.13(n=7$; ratio different from 1 with $p<0.01$; test across experiments). Thus, NMDA has a strong inhibitory effect on evoked IPSCs. This inhibition was accompanied by a clear and significant increase in the rate of failures, which on average rose from $0.41 \pm$ 0.04 in the control to $0.70 \pm 0.07$ in the presence of $15 \mu \mathrm{M}$ NMDA (paired $t$ test; $p<0.02$; Fig. 8). Therefore, the inhibition in overall IPSC size results at least in part from a reduced probability of release. Nevertheless, there was no systematic effect of NMDA on paired-pulse ratio (Fig. 8). The lack of effect of NMDA on paired pulse ratio is, however, compatible with a presynaptic effect. It was earlier shown that depolarization-induced suppression of inhibition (DSI), which is a form of presynaptic inhibition, does not involve any change of paired pulse ratio, and it was suggested that this reflects axonal conduction block during DSI (Alger et al., 1996).

\section{DISCUSSION}

\section{NMDA-induced potentiation of mIPSC frequency}

The principal result of this study is that NMDA increased the frequency of mIPSCs recorded in both interneurons and Purkinje cells. The frequency of mEPSCs in either cell type was not modified, and the mIPSC frequency increase was considerably larger in interneurons than in Purkinje cells, indicating that this action of NMDA is specific for the nature of both presynaptic and postsynaptic neurons.
In Purkinje cells, NMDA preferentially increased the frequency of small mIPSCs. This might reflect a differential NMDA-induced potentiation of GABA release at a distinct subset of synapses that mediate small synaptic currents, whereas other synapses with larger mIPSCs are less affected by NMDA. The alternative possibility, that the change of mean mIPSC amplitude would be postsynaptic, is very unlikely because Purkinje cells do not respond to NMDA in the age group examined here (Farrant and Cull-Candy, 1991; Llano et al., 1991; Rosenmund et al., 1992; confirmed by present study).

Despite abundant morphological evidence for the presence of presynaptic glutamate ionotropic receptors in brain slices, little attention has been given to the potential functional role of such receptors. However, it was recently proposed that presynaptic kainate receptors inhibit neurotransmitter release in the hippocampus (Chittajallu et al., 1996; Clarke et al., 1997; RodríguezMoreno et al., 1997). Even more recently, in the preparation used in the present study, Bureau and Mulle (1998) found a potentiating effect of AMPA receptors on spontaneous IPSCs, which was resistant to the addition of TTX and which was considered as resulting from the activation of axonal AMPA-selective receptors. These findings, together with those of the present work, suggest that both NMDA-selective and AMPA-selective subtypes of ionotropic glutamate receptors are present in the axons of cerebellar interneurons, and that the activation of both receptor subtypes leads to enhanced spontaneous GABA release. Interestingly, the effects of AMPA receptor activation are maximal near the age used in the present study, and they wane during further development (Bureau and Mulle, 1998). We have not tested developmental changes in the present study.

Because addition of D-APV decreases the rate of mIPSCs, the concentration of background glutamate appears sufficient to exert a tonic action on the rate of mIPSCs. Thus, one function of presynaptic NMDARs could be to regulate the interneuroninduced inhibition of Purkinje cells according to the glutamate concentration in the molecular layer.

\section{Inhibition of evoked IPSCs}

IPSCs evoked in interneurons after extracellular stimulation in the molecular layer were severely inhibited by NMDA (Fig. 8). Thus, NMDA has opposite effects on miniature and evoked synaptic currents, as previously found when analyzing the effects 
of noradrenaline in interneurons (Kondo and Marty, 1998). In other mammalian brain preparations, it was found that activation of kainate receptors inhibits both miniature (Rodríguez-Moreno et al., 1997) and evoked synaptic currents (Chittajallu et al., 1996; Clarke et al., 1997; Rodríguez-Moreno et al., 1997). In the present experiments, the inhibition of evoked IPSCs was not caused by activation of $\mathrm{GABA}_{\mathrm{B}}$ receptors after enhanced GABA liberation, because it was insensitive to the $\mathrm{GABA}_{\mathrm{B}}$ blocker CGP 62349. Still, the inhibitory effect could be indirect, and could be caused by presynaptic $\mathrm{GABA}_{\mathrm{A}}$ receptors, or by other neurotransmitters than GABA, such as glutamate, which might be liberated by NMDA. Alternatively, the inhibition could result directly from the activation of axonal NMDARs, which could elevate the threshold for action potential firing, increase the probability of transmission failure in the axon, or reduce the probability of evoked GABA release by some other mechanisms (which could involve a long-lasting elevation in axonal calcium concentration). Sorting out these various possibilities is outside the scope of the present work.

\section{$\mathbf{M g}^{2+}$ dependence of NMDA effect}

A characteristic trait of the NMDAR is that it is blocked by external $\mathrm{Mg}^{2+}$ in a voltage-dependent manner. The extent of the block depends on the composition of the NMDAR subunits (Kutsuwada et al., 1992; Monyer et al., 1992; Ishii et al., 1993; Monyer et al., 1994; Kuner and Schoepfer, 1996; Casado et al., 1996). The ratio of the increase of mIPSC frequency in the absence of any added $\mathrm{Mg}^{2+}$ and in the presence of $1 \mathrm{mM} \mathrm{Mg} \mathrm{Mg}^{2+}$ was about five in this study (for $10 \mu \mathrm{M}$ NMDA; Fig. 4). This value compares well with the corresponding average ratio of 6.5 of currents through recombinant NMDARs containing the NMDAR2C and D subunit, whereas the average of the ratio of currents through recombinant NMDARs containing the NMDAR2A and B subunit was about 17 (Ishii et al., 1993; Monyer et al., 1994; Kuner and Schoepfer, 1996). An in situ hybridization study revealed the presence of NMDAR2D subunits in cells of the molecular layer that were tentatively identified as interneurons (Akazawa et al., 1994). NMDARs containing the 2D subunit could therefore underlie the increase in synaptic activity that we have observed.

\section{TTX-insensitive effects are not necessarily presynaptic}

The usual distinction between presynaptic and postsynaptic effects in mammalian brain preparations is based on the use of TTX, which is considered to uncouple the somatodendritic and the axonal domains of presynaptic neurons. On this basis, any drug that changes the frequency of miniatures in the presence of TTX is assumed to act "presynaptically", i.e., in the axonal domain of the presynaptic cell.

One important assumption behind this analysis is that TTX effectively blocks the generation of action potentials in the presynaptic cell. The concentration of TTX that was used in our experiments is clearly sufficient to abolish voltage-dependent $\mathrm{Na}^{+}$currents in interneurons (Llano and Gerschenfeld, 1993; present experiments). In addition, we verified in current-clamp conditions that no sign of regenerative depolarization could be obtained in somatic recordings of interneurons either in TTX alone or after addition of NMDA. Therefore, interneurons are unable to fire either $\mathrm{Na}^{+}$- or $\mathrm{Ca}^{2+}$-dependent action potentials in the presence of TTX.

A second, usually tacit assumption is that potential changes linked to activation of somatodendritic receptors are not passively transmitted to release sites in the presence of TTX. This is a reasonable assumption if the distance between soma and presynaptic release sites is large. However, a large proportion of release sites of stellate and basket cells are located at $<100 \mu \mathrm{m}$ from the soma (Bishop, 1993; Pouzat and Kondo, 1996), raising the possibility of a passive transfer of depolarization along the axon cable. Here we performed paired recordings of interneuronPurkinje cell synapses in TTX, and found that somatic depolarization does influence release sites, leading to an increase in the frequency of mIPSCs (Fig. 6). This result calls for caution in the traditional distinction between presynaptic and postsynaptic effects based on the use of TTX.

\section{Is the increase in MIPSC frequency mediated by somatodendritic or axonal NMDARs?}

The finding that depolarization can be transmitted from the soma of interneurons to release sites raises the possibility that somatodendritic NMDARs could be responsible for the enhancement in mIPSC frequency recorded in interneurons and Purkinje cells. If this were the case, then the effects of NMDA on mIPSC frequency should be mimicked by depolarizing the soma of presynaptic neurons to the same extent as in the presence of NMDA. This possibility can be tested by a quantitative evaluation of the results of paired basket cell-Purkinje cell recordings. In these experiments, we measured the "weight" of individual basket cell-Purkinje cell connections as explained in Results, to estimate the part of the synaptic input contributed by a single basket cell. The mean of these weights was $13 \%$. Next we found that on average $30 \mu \mathrm{M}$ NMDA depolarized interneurons by $11 \mathrm{mV}$. From the data in Figure 6 this depolarization translates to an increase in mIPSC frequency by $8 \%$. Therefore, the $11 \mathrm{mV}$ that are measured in the presence of NMDA should induce an increase by $8 / 0.13=62 \%$ of the mIPSC frequency. Experimentally, an increase by $465 \%$ is found (Fig. 4), 7.5-fold higher than this estimate. This discrepancy is unlikely to be caused by cell-to-cell heterogeneity, because responses to NMDA were homogeneous within interneurons. Furthermore, because interneuron-Purkinje cell distances were minimized in paired experiments, the degree of electrotonic coupling between soma and terminals that was measured is certainly higher than that pertaining on average at interneuron-Purkinje cell synapses, so that the actual discrepancy must be larger than the estimated 7.5 factor. This indicates that the somatodendritic depolarization resulting from the activation of NMDARs is not sufficient to account for the effects on mIPSC frequency that are obtained. Therefore, the receptors responsible for the increase in $\mathrm{mIPSC}$ frequency are probably mostly located in the axonal domain of the cell. This proposal is supported by the recent finding of NMDAR immunostaining in the pinceau region of basket cell terminals onto Purkinje cells (Petralia et al., 1994).

\section{REFERENCES}

Akazawa C, Shigemoto R, Bessho Y, Nakanishi S, Mizuno N (1994) Differential expression of five $N$-methyl-D-aspartate receptor subunit mRNAs in the cerebellum of developing and adult rats. J Comp Neurol 347:150-160.

Alger BE, Pitler TA, Wagner JJ, Martin LA, Morishita W, Kirov SA, Lenz RA (1996) Retrograde signalling in depolarization-induced suppression of inhibition in rat hippocampal CA1 cells. J Physiol (Lond) 496:197-209.

Aoki C, Venkatesan C, Go C, Mong JA, Dawson TM (1994) Cellular and subcellular localization of NMDA-R1 subunit immunoreactivity in the visual cortex of adult and neonatal rats. J Neurosci 14:5202-5222. Berretta N, Jones RSG (1996) Tonic facilitation of glutamate release by 
presynaptic $N$-methyl-D-aspartate autoreceptors in the entorhinal cortex. Neuroscience 75:339-344.

Bishop GA (1993) An analysis of HRP-filled basket cell axons in the cat's cerebellum. I. Morphometry and configuration. Anat Embryol 188:287-297.

Bureau I, Mulle C (1998) Potentiation of gabaergic synaptic transmission by AMPA receptors in mouse cerebellar stellate cells: changes during development. J Physiol (Lond) 509:817-831.

Casado M, Guajardo-López A, Mellström B, Naranjo JR, Lerma J (1996) Functional $N$-methyl-D-aspartate receptors in cloned rat phaeochromocytoma cells. J Physiol (Lond) 490:391-404.

Chittajallu R, Vignes M, Dev KK, Barnes JM, Collingridge GL, Henley JM (1996) Regulation of glutamate release by presynaptic kainate receptors in the hippocampus. Nature 379:78-81.

Clarke VRJ, Ballyk BA, Hoo KH, Mandelzys A, Pellizzari A, Bath CP, Thomas J, Sharpe EF, Daies CH, Ornstein PL, Schoepp DD, Kamboj RK, Collingridge GL, Lodge D, Bleakman D (1997) A hippocampal GluR5 kainate receptor regulating inhibitory synaptic transmission. Nature 389:599-603.

Cochilla AJ, Alford S (1997) Glutamate receptor-mediated synaptic excitation in axons of the lamprey. J Physiol (Lond) 499:443-457.

Collingridge GL, Herron CE, Lester RAJ (1988) Synaptic activation of $N$-methyl-D-aspartate receptors in the Schaffer collateral-commissural pathway of rat hippocampus. J Physiol (Lond) 399:283-300.

Collingridge GL, Singer W (1990) Excitatory amino acid receptors and synaptic plasticity. Trends Pharmacol 11:290-296.

DeBiasi S, Minelli A, Melone M, Conti F (1996) Presynaptic NMDA receptors in the neocortex are both auto- and heteroreceptors. NeuroReport 7:2773-2776.

Dieudonné S (1995) Glycinergic synaptic currents in Golgi cells of the rat cerebellum. Proc Natl Acad Sci 92:1441-1445.

Farb CR, Aoki C, Ledoux JE (1995) Differential localization of NMDA and AMPA receptor subunits in the lateral and basal nuclei of the amygdala: a light and electron microscopic study. J Comp Neurol 362:86-108.

Farrant M, Cull-Candy SG (1991) Excitatory amino acid receptorchannels in Purkinje cells in thin cerebellar slices. Proc R Soc Lond B Biol Sci 244:179-184.

Fu W, Liou J, Lee Y, Liou H (1995) Potentiation of neurotransmitter release by activation of presynaptic glutamate receptors at developing neuromuscular synapses of Xenopus. J Physiol (Lond) 489:813-823.

Glitsch M, Llano I, Marty A (1996) Glutamate as a candidate retrograde messenger at interneurone-Purkinje cell synapses of rat cerebellum. J Physiol (Lond) 479:531-537.

Hestrin S, Nicoll RA, Perkel DJ, Sah P (1990) Analysis of excitatory synaptic action in the rat hippocampus using whole cell recording from thin slices. J Physiol (Lond) 422:203-225.

Ishii T, Moriyoshi K, Sugihara H, Sakurada K, Kadotani H, Yokoi M, Akazawa C, Shigemoto R, Mizuno N, Masu M, Nakanishi S (1993) Molecular characterization of the family of the $N$-methyl-D-aspartate receptor subunits. J Biol Chem 268:2836-2843.

Kondo S, Marty A (1998) Differential effects of noradrenaline on evoked, spontaneous and miniature IPSCs in rat cerebellar stellate cells. J Physiol (Lond) 509:233-243.

Krebs MO, Desce JM, Kemel ML, Gauchy C, Godeheu G, Cheramy A, Glowinski J (1991) Glutaminergic control of dopamine release in the rat striatum: evidence for presynaptic $N$-methyl-D-aspartate receptors on dopaminergic nerve terminals. J Neurochem 56:81-85.

Kuner T, Schoepfer R (1996) Multiple structural elements determine subunit specificity of $\mathrm{Mg}^{2+}$ block in NMDA receptor channels. J Neurosci 16:3549-3558.

Kutsuwada T, Kashiwabuchi N, Mori H, Sakimura K, Kushiya E, Araki K, Meguro H, Masaki H, Kumanishi T, Arakawa M, Mishina M (1992) Molecular diversity of the NMDA receptor channel. Nature 358:36-41.
Liu H, Wang H, Sheng M, Jan LY, Jan YN, Basbaum AI (1994) Evidence for presynaptic $N$-methyl-D-aspartate autoreceptors in the spinal cord dorsal horn. Proc Natl Acad Sci 91:8383-8387.

Llano I, Gerschenfeld HM (1993) Inhibitory synaptic currents in stellate cells of rat cerebellar slices. J Physiol (Lond) 468:177-200.

Llano I, Marty A, Armstrong CM, Konnerth A (1991) Synaptic and agonist-induced excitatory currents of Purkinje cells in rat cerebellar slices. J Physiol (Lond) 434:183-213.

Llano I, Tan YP, Caputo C (1997) Spatial heterogeneity of intracellular $\mathrm{Ca}^{2+}$ signals in axons of basket cells from rat cerebellar slices. J Physiol (Lond) 502:509-519.

Llinas RR, Walton KD (1990) Cerebellum. In: the synaptic organization of the brain (Shepherd GM, ed), pp 214-245. Oxford: Oxford UP.

Marty A, Llano I (1995) Modulation of inhibitory synapses in the mammalian brain. Curr Opin Neurobiol 5:335-341.

Mayer ML, Westbrook GL, Guthrie PB (1984) Voltage-dependent block by $\mathrm{Mg}^{2+}$ of NMDA responses in spinal cord neurones. Nature 309:261-263.

McGehee DS, Role LW (1996) Presynaptic ionotropic receptors. Curr Opin Neurobiol 6:342-349.

Meldrum B, Garthwaite J (1990) Excitatory amino acid neurotoxicity and neurodegenerative disease. Trends Pharmacol 11:379-387.

Monyer H, Sprengel R, Schoepfer R, Herb A, Higuchi M, Lomeli H, Burnashev N, Sakmann B, Seeburg PH (1992) Heteromeric NMDA receptors: molecular and functional distinction of subtypes. Science 256:1217-1221.

Monyer H, Burnashev N, Laurie DJ, Sakmann B, Seeburg PH (1994) Developmental and regional expression in the rat brain and functional properties of four NMDA receptors. Neuron 12:529-540.

Nowak L, Bregestovski P, Ascher P, Herbet A, Prochiantz A (1984) Magnesium gates glutamate-activated channels in mouse central neurones. Nature 307:462-465.

Palay SL, Chan-Palay V (1974) Cerebellar cortex: cytology and organization. New York: Springer.

Petralia RS, Wang Y-X, Wenthold RJ (1994) The NMDA receptor subunits NR2A and NR2B show histological and ultrastructural localization patterns similar to those of NR1. J Neurosci 14:6102-6120.

Pittaluga A, Raiteri M (1990) Release-enhancing glycine-dependent presynaptic NMDA receptors exist on noradrenergic terminals of hippocampus. Eur J Pharmacol 191:231-234.

Pouzat C, Kondo, S (1996) An analysis of neurobiotin-filled stellate cell axons in the rat cerebellum. Soc Neurosci Abstr 22:640.16.

Rodríguez-Moreno A, Herreras O, Lerma J (1997) Kainate receptors presynaptically downregulate GABAergic inhibition in the rat hippocampus. Neuron 19:893-901.

Rosenmund C, Legendre P, Westbrook GL (1992) Expression of NMDA channels on cerebellar Purkinje cells acutely dissociated from newborn rats. J Neurophysiol 68:1901-1905.

Schneggenburger R, Lopez-Barneo J, Konnerth A (1992) Excitatory and inhibitory synaptic currents and receptors in rat medial septal neurones. J Physiol (Lond) 445:261-276.

Stern P, Edwards FA, Sakmann B (1992) Fast and slow components of unitary EPSCs on stellate cells elicited by focal stimulation in slices of rat visual cortex. J Physiol (Lond) 449:247-278.

Vincent P, Marty A (1996) Fluctuations of inhibitory postsynaptic currents in Purkinje cells from rat cerebellar slices. J Physiol (Lond) 494:183-199.

Wang JKT (1991) Presynaptic NMDA receptors modulate dopamine release from striatal synaptosomes. J Neurochem 57:819-822.

Wang JKT, Andrews H, Thukral V (1992) Presynaptic NMDA receptors regulate noradrenaline release from isolated nerve terminals. J Neurochem 58:204-211. 